\title{
A Mobile App for Self-Triage for Pediatric Emergency Patients in Japan: 4 Year Descriptive Epidemiological Study
}

Yusuke Katayama ${ }^{1}, \mathrm{MD}, \mathrm{PhD}$; Kosuke Kiyohara ${ }^{2}$, DrPH; Tomoya Hirose ${ }^{1}, \mathrm{MD}, \mathrm{PhD}$; Tasuku Matsuyama ${ }^{3}, \mathrm{MD}$, $\mathrm{PhD}$; Kenichiro Ishida ${ }^{4}, \mathrm{MD}$; Shunichiro Nakao ${ }^{1}, \mathrm{MD}, \mathrm{MSc}$; Jotaro Tachino ${ }^{1}$, MD; Masahiro Ojima ${ }^{4}$, MD; Tomohiro Noda $^{5}$, MD; Takeyuki Kiguchi ${ }^{6}$, MD, PhD; Sumito Hayashida ${ }^{7}$;etsuhisa Kitamura ${ }^{8}$, MD, DrPH; Yasumitsu Mizobata ${ }^{5}$, MD, PhD; Takeshi Shimazu ${ }^{1}, \mathrm{MD}, \mathrm{PhD}$

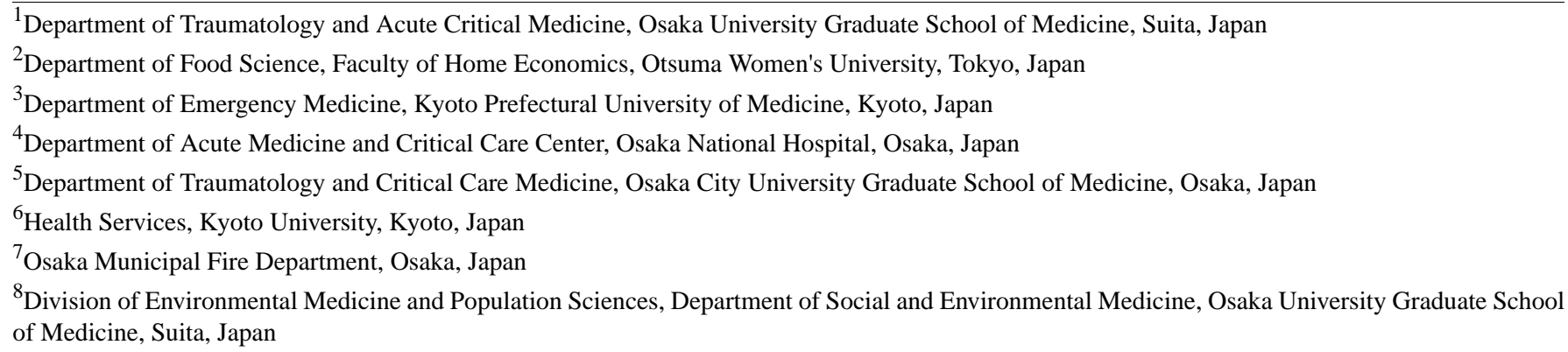

\section{Corresponding Author:}

Yusuke Katayama, MD, PhD

Department of Traumatology and Acute Critical Medicine

Osaka University Graduate School of Medicine

2-15

Yamada-oka

Suita, 5650871

Japan

Phone: 811668795707

Fax: 81668795705

Email: orion13@hp-emerg.med.osaka-u.ac.jp

\section{Abstract}

Background: When children suffer sudden illness or injury, many parents wonder whether they should go to the hospital immediately or call an ambulance. In 2015, we developed a mobile app that allows parents or guardians to determine the urgency of their child's condition or call an ambulance and that indicates available hospitals and clinics when their child is suddenly sick or injured by simple selection of the child's chief complaints and symptoms. However, the effectiveness of medical apps used by the general public has not been well evaluated.

Objective: The purpose of this study was to clarify the use profile of this mobile app based on data usage in the app.

Methods: This study was a descriptive epidemiological study with a 4-year study period running from January 2016 to December 2019. We included cases in which the app was used either by the children themselves or by their parents and other guardians. Cases in which the app was downloaded but never actually used were excluded from this study. Continuous variables are presented as median and IQR, and categorical variables are presented as actual number and percentages.

Results: The app was used during the study period for 59,375 children whose median age was 1 year (IQR 0-3 years). The app was used for 33,874 (57.05\%) infants, 16,228 (27.33\%) toddlers, $8102(13.65 \%)$ elementary school students, and $1117(1.88 \%)$ junior high school students, with $54(0.09 \%)$ having an unknown status. Furthermore, 31,519 (53.08\%) were male and 27,329 $(46.03 \%)$ were female, with sex being unknown for 527 (0.89\%) children. "Sickness" was chosen for 49,101 (78.51\%) patients, and "injury, poisoning, foreign, substances and others" was chosen for 13,441 (21.49\%). For "sickness," "fever" was the most commonly selected option $(22,773,36.41 \%)$, followed by "cough" (4054, 6.48\%), and "nausea/vomiting" (3528, 5.64\%), whereas for "injury, poisoning, foreign substances and others," "head and neck injury" was the most commonly selected option (3887, $6.22 \%)$, followed by "face and extremities injury" (1493, 2.39\%) and "injury and foreign substances in eyes" (1255, 2.01\%). 
Conclusions: This study clarified the profile of use of a self-triage app for pediatric emergency patients in Japan.

(JMIR Pediatr Parent 2021;4(2):e27581) doi: $\underline{10.2196 / 27581}$

\section{KEYWORDS}

emergency medicine; self-triage; mobile app; children; telemedicine; app; mobile health; mHealth; epidemiology

\section{Introduction}

When children suffer sudden illness or injury, many parents wonder whether they should go to the hospital immediately or call for an ambulance. When they cannot make the decision, they often call for an ambulance, which is one of the reasons why the number of ambulance calls has increased in recent years [1]. Telephone triage services have been introduced to replace various ambulance calls around the world. In the United Kingdom, the National Health Service (NHS) operates a telephone consultation service for people with sudden illness or injury [2]. In Australia, when a patient contacts the emergency dispatch center, secondary telephone triage is conducted after primary triage has taken place [3]. In Japan, telephone triage services for sudden illness and injury have been provided to people mainly in urban areas such as Tokyo and Osaka [4,5]. Osaka Prefecture is one of the largest metropolitan areas in Japan with a population of 8.8 million [6], and the number of ambulance dispatches in this area in 2016 was approximately 600,000 [7]. The Osaka Municipal Fire Department has been operating a telephone triage service (\#7119) since 2012 [5]. The number of calls to the telephone triage center in Osaka has been increasing year by year, with the number totaling 284,665 in 2019 [8]. Correspondingly, the use of the telephone triage service has increased, especially during holiday seasons when few medical institutions are open, and this has caused some problems, such as difficulty in connecting to the telephone triage service due to line congestion.

In 2015, we developed a mobile app in Osaka Prefecture that allows parents or guardians to determine the urgency of their child's condition and call for an ambulance, and which indicates available hospitals and clinics when their child is suddenly sick or injured by having the parents simply select the child's chief complaints and symptoms. This application has been available in Japan for free download from the Google Play Store and Apple App Store since 2016. The information on available hospitals and clinics that can be displayed in this app is limited to Osaka Prefecture. The widespread use of this mobile app to advise parents and guardians and provide necessary support in the event of sudden illness and injury would enable us to conduct medical services more effectively and to reduce unnecessary ambulance calls and medical costs. In addition, the use of this mobile app may provide assurance to those parents and guardians who have children or dependents with health issues. Clarifying how such a mobile app is used is important for assessing the usefulness of medical mobile apps. Therefore, the purpose of this study was to clarify the profile of the use of this mobile app based on data usage in the app.

\section{Methods}

\section{Study Design, Population, and Setting}

This was a descriptive epidemiological study whose 4-year study period ran from January 2016 to December 2019. In 2015, 17.08 million children were under 15 years old in Japan [6], of whom 1.17 million resided in Osaka Prefecture [6]. We included cases in which the app was used either by the children themselves or by their parents and other guardians in this study. The cases who downloaded the mobile app but never actually used it were excluded from our analysis.

\section{Telephone Triage Services and Triage Protocol in Osaka Prefecture and Japan}

In Japan, there are triage protocols including the Japanese Triage Acuity Scale [9], which is based on the Canadian Triage Acuity Scale, and the Emergency Assessment Protocol [10] established by the Fire and Disaster Management Agency for assessing and triaging emergency patients. Telephone triage services provided in some areas of Japan use the Emergency Assessment Protocol.

The telephone triage service in Osaka Prefecture has been described previously in detail $[5,11]$. The telephone triage nurses who receive phone calls from people judge the urgency of the chief complaints using software based on the Emergency Assessment Protocol. In Japan, there are 97 different protocols for judging the urgency by chief complaints [10], and the urgency is determined by selecting the signs and symptoms related to the chief complaint. In the mobile app reported here, we selected the 20 protocols from the Emergency Assessment Protocol in Osaka that were the most frequently used in the telephone triage service in Osaka Prefecture for "sickness" and "injury, poisoning, foreign substances and others" (Textbox 1) and modified some of the wording to make it easier for general users to understand. 
Textbox 1. Chief complaints listed in the mobile app.

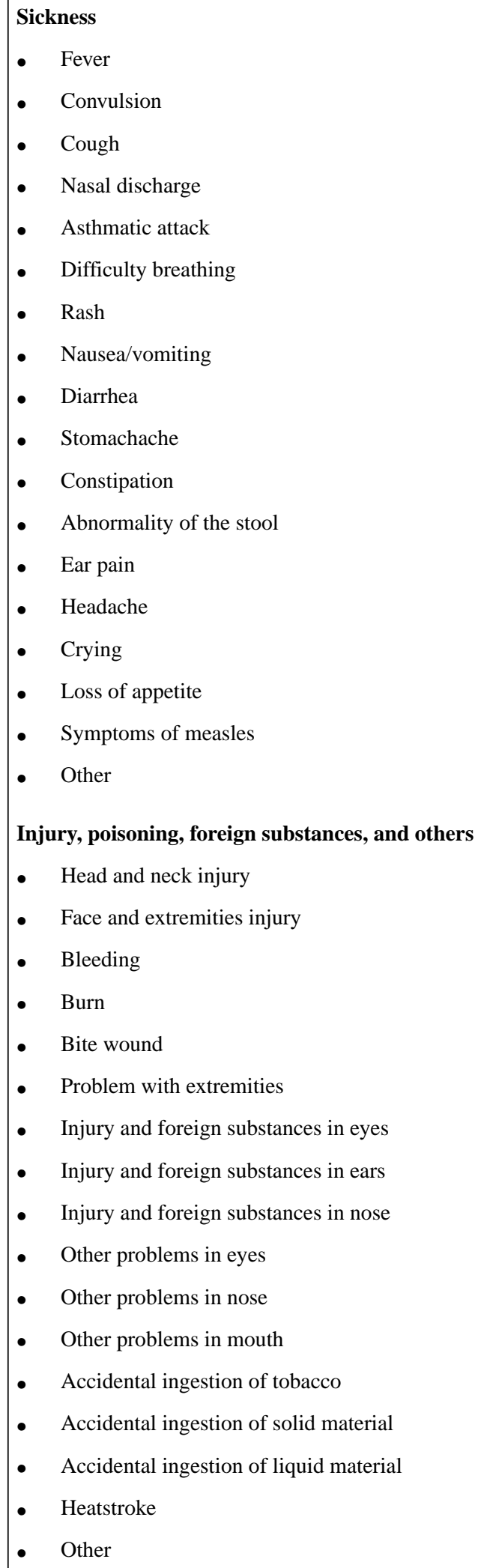

\section{Mobile App for Emergency Pediatric Patients}

Figure 1 shows the flow chart of the mobile app. The first step in this app is to select the age and gender of the child. Next, the user selects either "sickness" or "injury, poisoning, foreign substances and others." When either of these is selected, the list of chief complaints shown in Textbox 1 is displayed in the app, and the user selects the relevant chief complaint. For example, if "fever" is selected, relevant signs and symptoms with high urgency such as, "fever of $41^{\circ} \mathrm{C}$ or higher," are displayed in the app. If none of these are selected, relevant signs and symptoms with moderate urgency such as, "decreased urine volume," are 
displayed in the app. If none of them apply, the related signs and symptoms corresponding to "low urgency" are further displayed, and the urgency is determined based on the selected signs and symptoms. The app provides emergency medical services, such as the ability to call an ambulance or the telephone triage center and information on available hospitals and clinics. If there is another chief complaint, such as "convulsion," when "fever" is selected, the app will move to the urgency assessment for the other complaint (Figures 2-7). Only hospitals and clinics in Osaka Prefecture that have agreed to register their information in the app will be displayed as available hospitals and clinics.
In addition, the GPS feature of the user's cellphone also provides a list of hospitals and clinics in order of proximity to the location where the app is being used. During the mobile app development, we asked some mothers for their opinions about the usefulness of this mobile app, and modified the interface of the mobile app. The Android version of this app was released in January 2016, and the iOS version was released in April 2016 for free download. As for the algorithms used in this mobile app, we provided the algorithm for "fever" as one of examples (Table S1, Multimedia Appendix 1).

Figure 1. Flowchart of the mobile app.

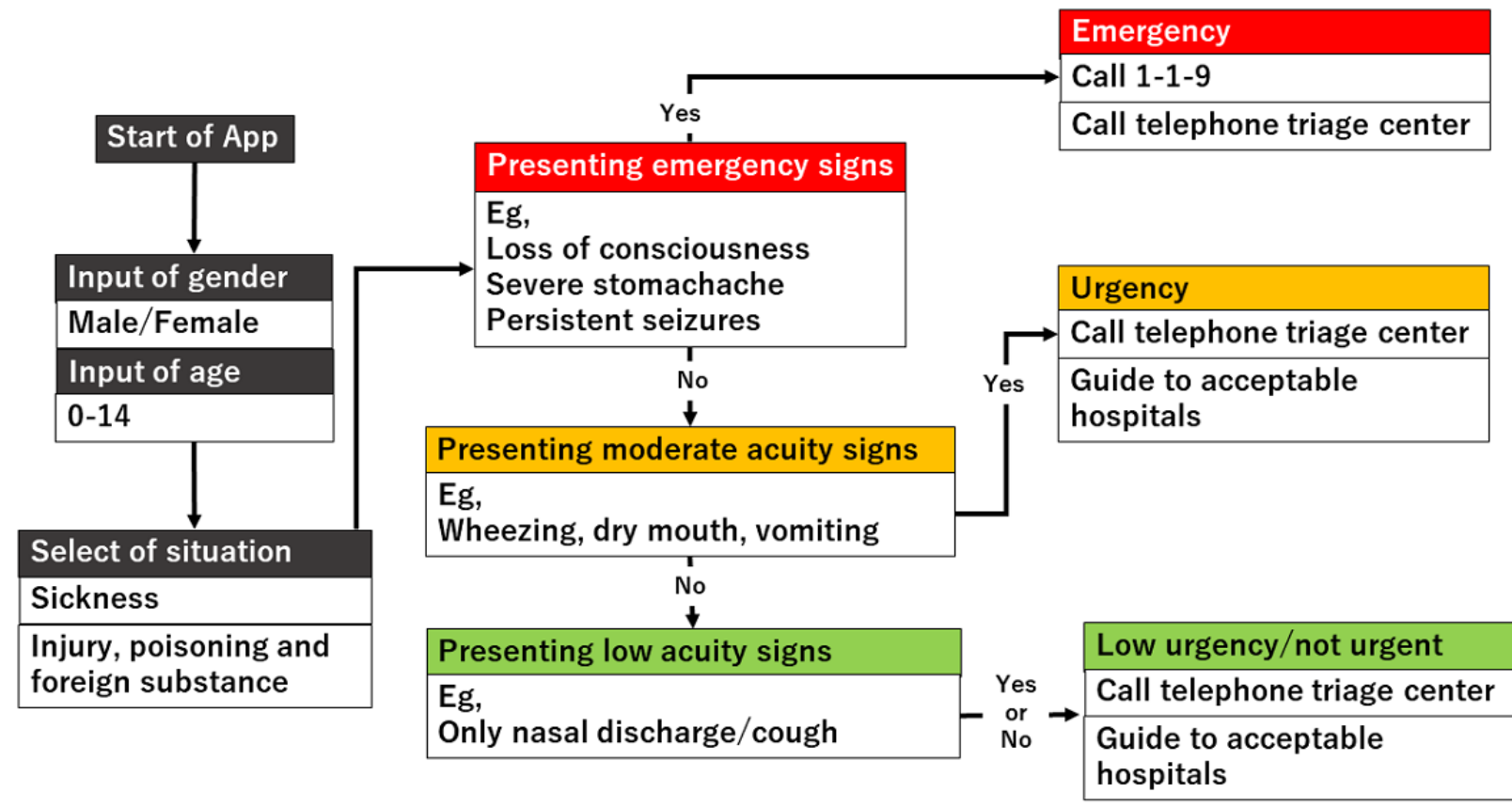


Figure 2. Screenshot of patient input about age and sex.

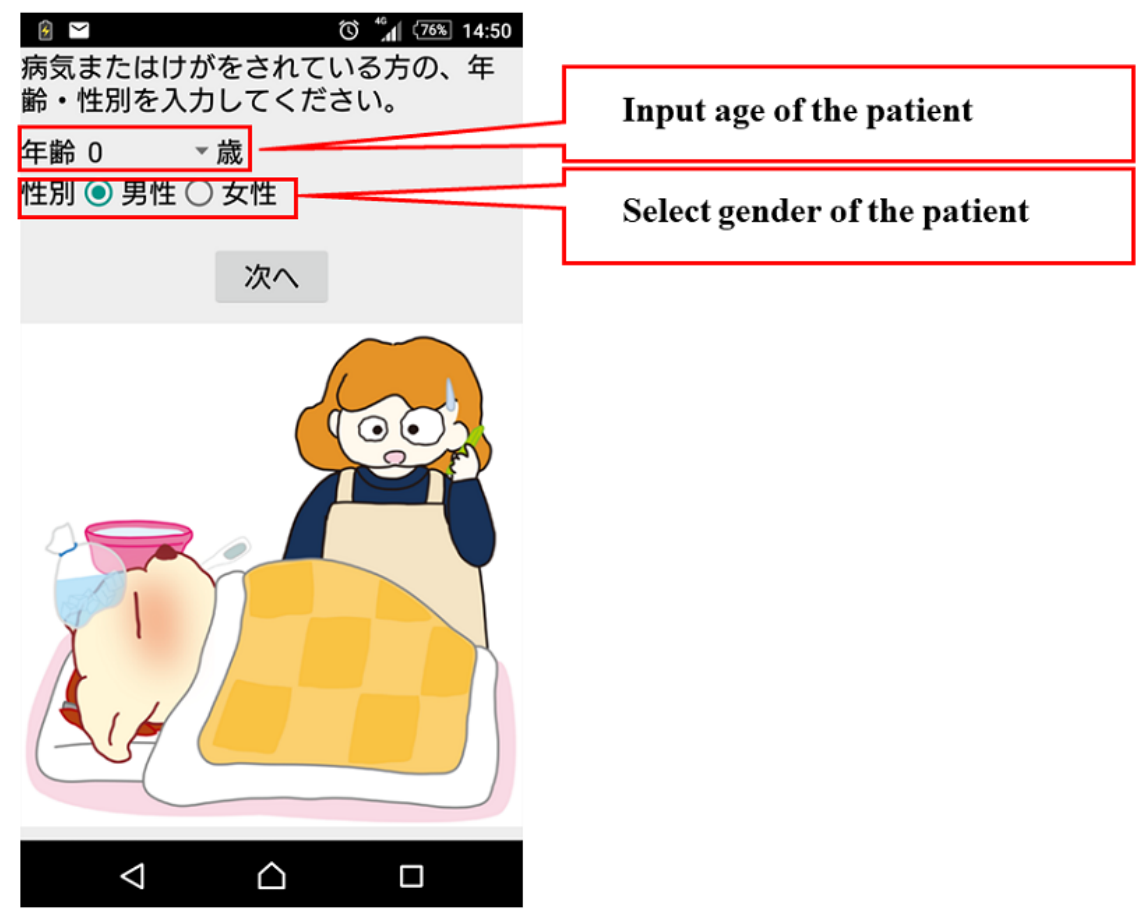

Figure 3. Screenshot of selection about "Sickness" or "Injury, poison, foreign substances and others".

\begin{tabular}{|c|c|}
\hline $\begin{array}{l}\text { 目曰ロ } \\
\text { 該当する症状をタップして } \\
\text { どちらですか? }\end{array}$ & ください。 \\
\hline 病気 & \\
\hline $\begin{array}{l}\text { けが・異物 } \\
\text { (中毒、熱中症を含む) }\end{array}$ & \\
\hline
\end{tabular}

Select "Sickness" or

"Injury, poison,

foreign substances and others"

れ緊急性があると思った場合は、

すぐに「119」へ!

（呼吸や脈、意識がないなど）

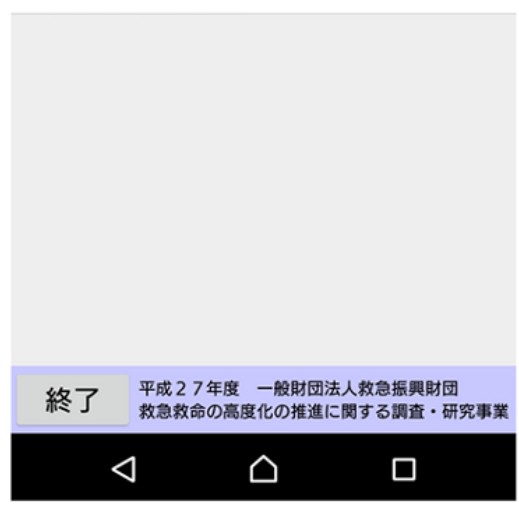


Figure 4. Screenshot of chief complaint selection.

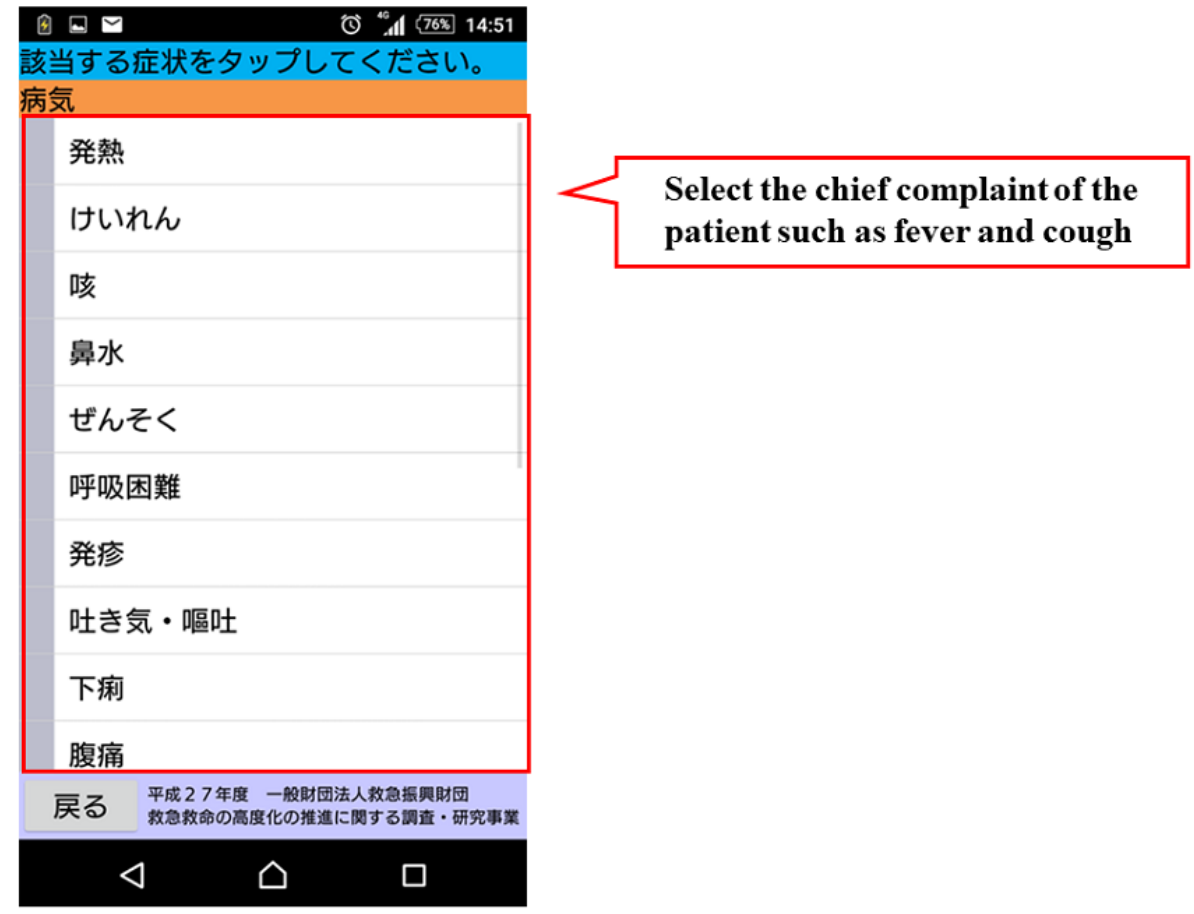

Figure 5. Screenshot about selection of signs and symptoms related to the selected chief complaint.

\begin{tabular}{|c|c|}
\hline \multicolumn{2}{|c|}{ 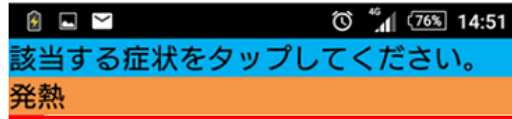 } \\
\hline \multicolumn{2}{|c|}{41 ํ以上の発熱がある。 } \\
\hline \multicolumn{2}{|c|}{$\begin{array}{l}\text { 一日中ウトウトしている。興奮し } \\
\text { ている。暴れている }\end{array}$} \\
\hline \multicolumn{2}{|c|}{$\begin{array}{l}\text { 意識がもうろうとしている。おか } \\
\text { しなことを言う。 }\end{array}$} \\
\hline \multicolumn{2}{|c|}{$\begin{array}{l}\text { 生後 } 3 \text { カ月未満で } 38 \text { ํ以上の発 } \\
\text { 熱がある。 }\end{array}$} \\
\hline \multicolumn{2}{|c|}{$\begin{array}{l}\text { 特別な病気で熱が出たらすぐに病 } \\
\text { 院に来るように言われている。 }\end{array}$} \\
\hline \multicolumn{2}{|c|}{$\begin{array}{l}\text { 皮膚や唇が乾いていて、水分も十 } \\
\text { 分取れていない。 }\end{array}$} \\
\hline \multicolumn{2}{|c|}{$\begin{array}{l}\text { 暑いところにしばらくいた。激し } \\
\text { い運動の後。 }\end{array}$} \\
\hline 戻る & 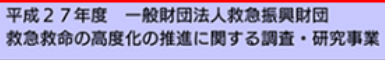 \\
\hline & $\triangle$ \\
\hline
\end{tabular}


Figure 6. Screenshot of result in emergency cases.

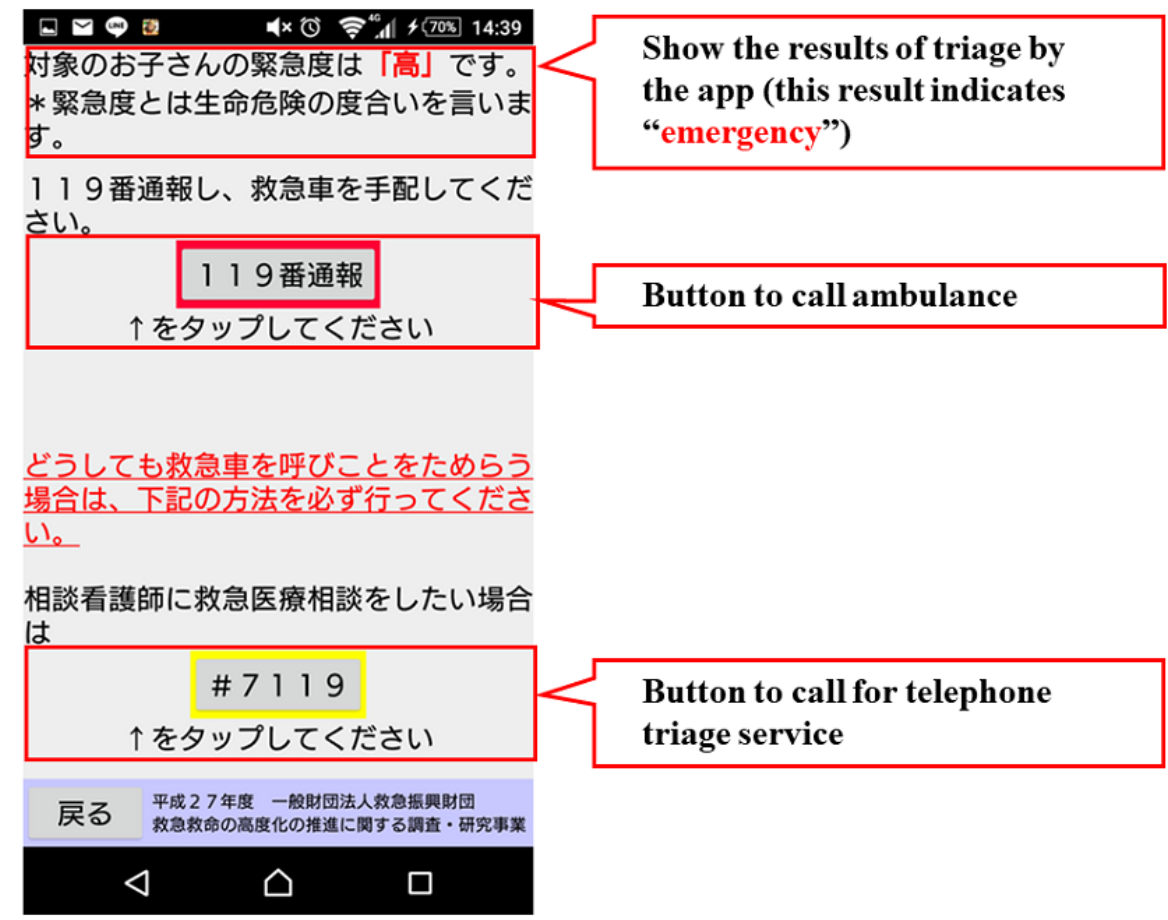

Figure 7. Screenshot of result in urgent cases.

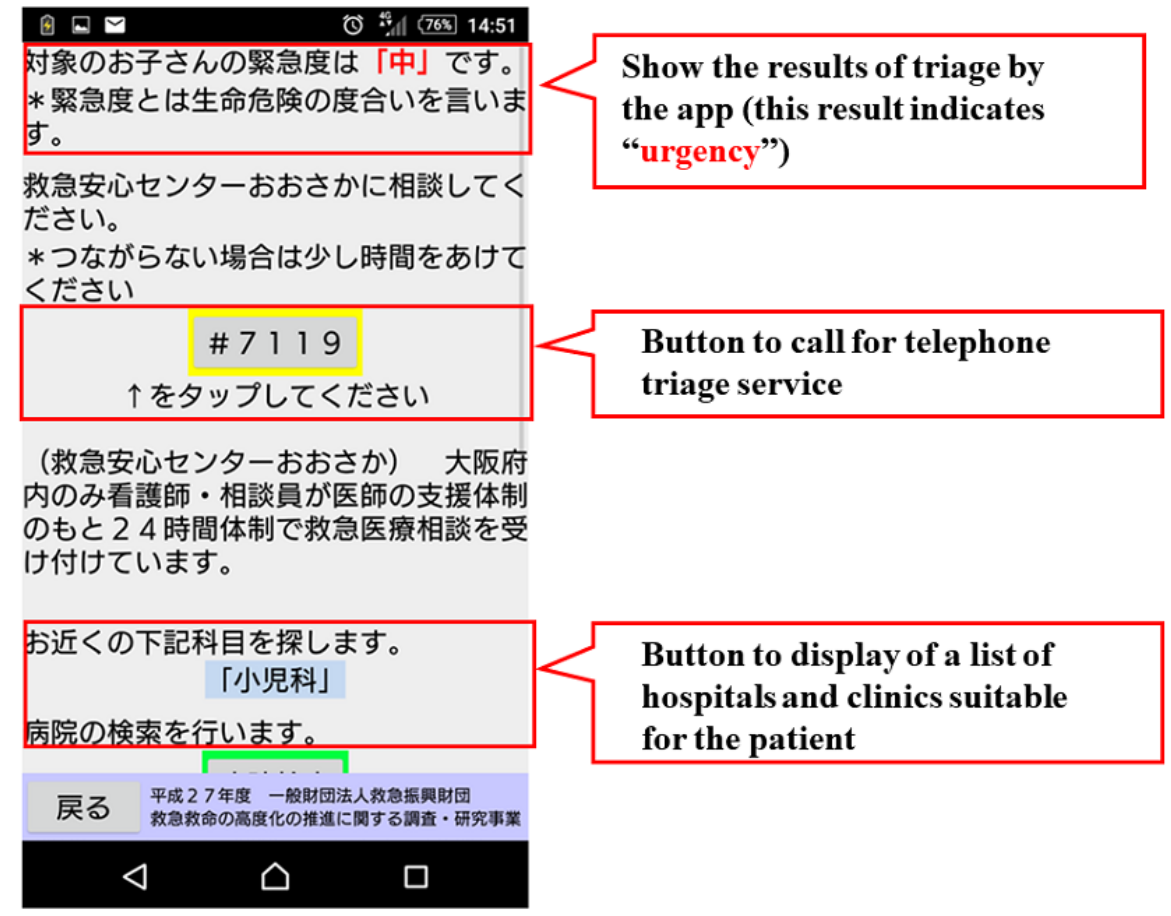

\section{Statistical Analysis}

Continuous variables are presented as median and IQR, and categorical variables are presented as actual number and percentages. Age groups were categorized as infants (0-1 years), toddlers (2-5 years), elementary school students (6-12 years), and junior high school students (13-15 years). The time of app use was categorized as midnight to 7:59 AM, 8 AM to 3:59 PM, and 4 PM to 11:59 PM. In this study, users who used the app multiple times were counted as a single user. The data used in this study were anonymized, but informed consent was obtained from the users at each occasion of use. This study was approved by the ethics committee of Osaka University Graduate School of Medicine (approval \#20313). This manuscript was written based on the Strengthening the Reporting of Observational Studies in Epidemiology (STROBE) statement [12]. 


\section{Results}

This mobile app was downloaded 24,721 times by December 2019, and we included 22,158 cases for this study, excluding about 2500 users who downloaded this mobile app but did not use it or uninstalled it before using it.

Table 1 shows the characteristics of the children for whom the app was used. The app was used from January 2016 to December 2019 for 59,375 children whose median age was 1 year (IQR 0-3 years). The app was used for 33,874 (57.05\%) infants, 16,228 (27.33\%) toddlers, $8102(13.65 \%)$ elementary school students, $1117(1.88 \%)$ junior high school students, and $54(0.09 \%)$ children of unknown status. Moreover, 31,519 $(53.08 \%)$ were male. The number of the children for whom the app was used was $10,105(17.02 \%)$ in $2016,13,077(22.02 \%)$ in $2017,17,877(30.11 \%)$ in 2018 , and 18,316 (30.85\%) in 2019. Regarding the time of day of app use, the app was used between midnight and 7:59 AM by 10,289 patients $(17.33 \%)$, between $8 \mathrm{AM}$ and 3:59 PM by 20,487 patients (34.50\%), and between
$4 \mathrm{PM}$ and 11:59 PM by 28,599 patients (48.16\%). The app was used by 33,887 patients $(57.07 \%)$ within Osaka Prefecture and by 5244 patients $(8.83 \%)$ outside of Osaka Prefecture. Location information was unknown for 20,244 patients (34.10\%).

Table 2 shows the clinical characteristics of the patients for whom the app was used. Among the 62,542 chief complaints selected, 49,101 (78.51\%) were "sickness" and 13,441 (21.49\%) were "injury, poisoning, foreign substances and others." Among "sickness," "fever" was the most commonly selected option $(22,773,36.41 \%)$, followed by "cough" $(4054,6.48 \%)$ and "nausea/vomiting" (3528, 5.64\%). Among "injury, poisoning, foreign substances and others," "head and neck injury" was the most commonly selected option $(3887,6.22 \%)$, followed by "face and extremities injury" (1493, 2.39\%) and "injury and foreign substances in eyes" (1255, 2.01\%).

Of the 4722 patients for whom some kind of emergency medical service was used, the most commonly selected option was "guide to acceptable hospitals and clinics" (3046/4722, 64.51\%; Table 3). 
Table 1. Demographic and geographic characteristics of the patients.

\begin{tabular}{|c|c|}
\hline Characteristics & $\begin{array}{l}\text { Value, } \mathrm{n}(\%) \\
(\mathrm{N}=59,375)\end{array}$ \\
\hline \multicolumn{2}{|l|}{ Age group } \\
\hline Infants ( $0-1$ years old $)$ & $33,874(57.05)$ \\
\hline Toddlers (2-5 years old) & $16,228(27.33)$ \\
\hline Elementary school students (6-12 years old) & $8102(13.65)$ \\
\hline Junior high school students (13-15 years old) & $1117(1.88)$ \\
\hline Unknown & $54(0.09)$ \\
\hline \multicolumn{2}{|l|}{ Gender } \\
\hline Male & $31,519(53.08)$ \\
\hline Female & $27,329(46.03)$ \\
\hline Unknown & $527(0.89)$ \\
\hline \multicolumn{2}{|l|}{ Year } \\
\hline 2016 & $10,105(17.02)$ \\
\hline 2017 & $13,077(22.02)$ \\
\hline 2018 & $17,877(30.11)$ \\
\hline 2019 & $18,316(30.85)$ \\
\hline \multicolumn{2}{|l|}{ Month } \\
\hline January & $4470(7.53)$ \\
\hline February & $3761(6.33)$ \\
\hline March & $3917(6.60)$ \\
\hline April & $4713(7.94)$ \\
\hline May & $5166(8.70)$ \\
\hline June & $5324(8.97)$ \\
\hline July & $5448(9.18)$ \\
\hline August & $5053(8.51)$ \\
\hline September & $5299(8.92)$ \\
\hline October & $4945(8.33)$ \\
\hline November & $4691(7.90)$ \\
\hline December & $6588(11.10)$ \\
\hline \multicolumn{2}{|l|}{ Time of day } \\
\hline Midnight-7:59 AM & $10,289(17.33)$ \\
\hline 8 AM-3:59 PM & $20,487(34.50)$ \\
\hline 4 PM-11:59 PM & $28,599(48.17)$ \\
\hline \multicolumn{2}{|l|}{ Day of the week } \\
\hline Sunday & $10,101(17.01)$ \\
\hline Monday & $8677(14.61)$ \\
\hline Tuesday & 7817 (13.17) \\
\hline Wednesday & 8031 (13.53) \\
\hline Thursday & 8764 (14.76) \\
\hline Friday & 7477 (12.59) \\
\hline Saturday & $8508(14.33)$ \\
\hline Area & \\
\hline
\end{tabular}




\begin{tabular}{ll}
\hline Characteristics & Value, $\mathrm{n}(\%)$ \\
& $(\mathrm{N}=59,375)$ \\
\hline Inside Osaka Prefecture & $33,887(57.07)$ \\
Outside Osaka Prefecture & $5244(8.83)$ \\
Unknown & $20,244(34.10)$ \\
\hline
\end{tabular}


Table 2. Clinical characteristics.

\begin{tabular}{|c|c|}
\hline Main presenting problem selected on the app & $\begin{array}{l}\text { Value, } \mathrm{n}(\%) \\
(\mathrm{N}=62,542)\end{array}$ \\
\hline Sickness & $49,101(78.51)$ \\
\hline Fever & $22,773(36.41)$ \\
\hline Convulsion & $2812(4.50)$ \\
\hline Cough & $4054(6.48)$ \\
\hline Nasal discharge & $2576(4.12)$ \\
\hline Asthmatic attack & $749(1.20)$ \\
\hline Dyspnea & $1414(2.26)$ \\
\hline Rash & $2217(3.54)$ \\
\hline Nausea/vomiting & $3528(5.64)$ \\
\hline Diarrhea & $2034(3.25)$ \\
\hline Stomachache & $959(1.53)$ \\
\hline Coprostasis & $684(1.09)$ \\
\hline Abnormal stool & $560(0.90)$ \\
\hline Ear pain & $793(1.27)$ \\
\hline Headache & $598(0.96)$ \\
\hline Crying & $1182(1.89)$ \\
\hline Anorexia & $472(0.75)$ \\
\hline Measles symptoms & $63(0.10)$ \\
\hline Symptoms of sicknesses & $1633(2.61)$ \\
\hline Injury, poisoning, foreign substances, and others & $13,441(21.49)$ \\
\hline Head and neck injury & $3887(6.22)$ \\
\hline Face and extremities injury & $1493(2.39)$ \\
\hline Bleeding & $350(0.56)$ \\
\hline Burn & $272(0.43)$ \\
\hline Bite wound & $76(0.12)$ \\
\hline Problem with extremities & $752(1.20)$ \\
\hline Injury and foreign substances in eyes & $1255(2.01)$ \\
\hline Injury and foreign substances in ears & $420(0.67)$ \\
\hline Injury and foreign substances in nose & $358(0.57)$ \\
\hline Other problems in eyes & $121(0.19)$ \\
\hline Other problems in nose & $150(0.24)$ \\
\hline Other problems in mouth & $516(0.83)$ \\
\hline Accidental ingestion of tobacco & $622(0.99)$ \\
\hline Accidental ingestion of solid material & $848(1.36)$ \\
\hline Accidental ingestion of liquid material & $235(0.38)$ \\
\hline Heatstroke & $1073(1.72)$ \\
\hline Other symptoms of injury, poisoning, foreign substances and others & $1013(1.62)$ \\
\hline
\end{tabular}


Table 3. Clinical characteristics.

\begin{tabular}{ll}
\hline Users' input & $\begin{array}{l}\text { Value, } \mathrm{n}(\%) \\
(\mathrm{n}=4722)\end{array}$ \\
\hline Call for ambulance & $33(0.7)$ \\
Call for telephone triage service & $422(8.9)$ \\
Call for medical consultation service of children & $3(0.1)$ \\
Guide to acceptable hospitals and clinics & $3046(64.5)$ \\
Observation & $1218(25.8)$ \\
\hline
\end{tabular}

\section{Discussion}

\section{Principal Results}

This study is the first to describe the profile of use of an emergency medical app available to the general public that guides them in the event of a child's sudden illness or injury. The app was most frequently used for infants, and it was used most frequently between 4 PM and 11:59 PM and on Sundays. In addition, about half of the uses were in Osaka Prefecture. The most common medical advice selected was "guide to acceptable hospitals and clinics." This study would be useful in the development of medical apps that can be used on mobile devices for nonmedical personnel.

We previously described the profile of patients who were transported by ambulance after telephone triage in Osaka Prefecture [5]. The most common time of day for both telephone triage and use of this app was in the evening. In Japan, some nighttime emergency clinics provide primary emergency care after many general clinics close in the evening. It is likely that when a child suddenly becomes sick or injured after clinics hours, parents use the telephone triage service or the app to decide whether they should visit a nighttime emergency clinic or emergency department immediately, call for an ambulance, or wait until the next day. This result was similar to the finding of a study of telenursing and an advice line in Australia [13]. In this study, about $57 \%$ of the users used this mobile app within Osaka Prefecture. The difference in the number of users within and outside of Osaka Prefecture might have been influenced not only by the available services, such as visiting medical institutions, but also by the public activities of the government. In Osaka Prefecture, the fire departments have not only publicized the mobile app through advertisements on trains and posters but also conducted activities to introduce the mobile app at events of basic life support for citizens. These government activities might have helped to increase awareness about this mobile app among citizens. In order to provide health services to citizens via mobile apps, it is essential for governments to repeatedly promote and educate the public.

The app assessed here not only judges urgency based on the selection of signs and symptoms but also provides medical help, such as ambulance calls and a guide to appropriate hospitals and clinics based on the results of the judgment. As a result, the number of users of this app has increased over the years, which indicates that not only the interface of this app but also the services it provides have been widely accepted by many users. There are several models that explain people's acceptance of new technologies. Venkatesh and colleagues [14] stated that the people's acceptance of new technologies is associated with 4 factors: performance expectancy, effort expectancy, social influence, and facilitating conditions (the Unified Theory of Acceptance and Use of Technology [UTAUT]). For example, performance expectancy is defined as the degree to which an individual believes that using the system will help him or her to attain gains in job performance. The emergency room system in the United States is not common in Japan. Therefore, when people suffer from sudden illness or injury, they have to use the phone or the internet to find hospitals and clinics by themselves. This mobile app assesses the urgency level of their selected symptoms and provides information on appropriate hospitals and clinics that can treat the patient. Hence, as it is more convenient to search than the traditional search for hospitals or clinics, people's performance expectancy is applicable to this mobile app. In addition, the effort expectancy is defined as the degree of simplicity associated with the use of a system. During the development of this mobile app, we asked a few mothers for their opinions about the usefulness of this mobile app, and modified the interface of the mobile app. Thus, although this mobile app was not always developed based on behavioral theories like UTAUT, some elements from these theories may be applicable.

\section{Comparison With Prior Work}

In this study, the number of ambulance calls made via the mobile app was low. In a previous study by Morimura and colleagues [15], $12.9 \%$ of patients who used the telephone triage services connected the phone to the ambulance dispatch center. The following may explain the discrepancy between this previous study and our own. First, Morimura et al's study included not only children but also adults and older adults, whereas we included only children in this study. Therefore, children might have been taken to a medical facility by their parents or guardians instead of by ambulance even when the urgency level of their symptoms was high. Second, the parents and guardians who used this mobile app might have only wanted to know the degree of urgency or whether or not they should visit a medical facility immediately. Indeed, only $7.95 \%(4722 / 59,375)$ of the population who used the mobile app used medical services, such as an ambulance call or an information search on medical institutions.

Many mobile apps for medical personnel have been developed in the field of pediatric emergency medicine. For instance, another study on medical app use in Irish pediatric emergency departments reported that one-third of medical facilities and about half of the medical personnel had medical apps installed 
on their personal mobile devices, with the most adopted app being the British National Formulary app developed by the NHS [16]. However, the effectiveness of medical apps used by the general public has not been well evaluated. In a review of 175 studies on medical apps that support self-management for the general public, only $30.3 \%$ of the apps were publicly available from app stores, the number of study participants was small (median number of study participants 31; IQR 11.0-29.2; maximum 11,690), and clinical outcomes were evaluated in only 36 studies (20.6\%) [17]. Another study comparing the effectiveness of an app, book, and video program on child health for parents visiting the emergency department reported that the app was not widely used, and the parents did not recommend the app to others [18]. For an app to be widely accepted by the general public, the effectiveness of the service provided by the app and an easy-to-use interface for users are essential. The app assessed here not only judges urgency based on the selection of signs and symptoms but also provides medical help through services like ambulance calls and guidance to appropriate hospitals and clinics based on the results of the assessment. As a result, the number of users of this app has increased over the years, which indicates that both the interface and services of the app have been widely accepted by many users. In addition, the number of app users is larger than that in previous studies, and thus, the general validity may also be high.

The purpose of this study was to determine the profile of use for this mobile app based on data usage in the app as mentioned in the Introduction; however, we did not evaluate the effectiveness of this mobile app. The app may have effects on the prognosis of patients as well as various other aspects, such as medical costs and the number of unnecessary ambulance calls. We are further planning to verify the efficacy of our mobile app through long-term monitoring or via a random interview survey to clarify other outcomes for users in the future, such as satisfaction of user experience.

\section{Limitations}

This study has several limitations. First, as the data entered into the app only came from users, it is possible that the data entered did not accurately reflect the patient's condition. Second, there were no data on the prognosis of any of the patients. Although the cooperation of users is essential for investigating the prognosis of the patients, there are legal problems in follow-up investigation. Moreover, this study did not ask for user demographics, and it was unclear whether a given user of the app was a parent or guardian. Third, compared to telephone triage, validation of the user's own triage using the app is problematic. We plan to examine this limitation in the future. Fourth, since the mobile app is, unfortunately, not yet sufficiently widespread in our target region, we must further make efforts to disseminate this app so that we can evaluate the effect of this app on ambulance calls and medical costs. Fifth, it was unclear to us whether users wanted to just try out the app or if they really wanted to use it. Sixth, demographics, including whether app users were adults, guardians, or the children themselves as well as other detailed information, such as average usage time and triage time, were not available in this study. Finally, we did not verify the validity of the of urgency assessment provided by this mobile app, which is something which should be determined in a future study.

\section{Conclusions}

In this study, we clarified the use profile of a self-triage app for pediatric emergency patients in Japan.

\section{Acknowledgments}

The authors are greatly indebted to all of the emergency medical services personnel working in the Osaka Municipal Fire Department. We also thank our colleagues from Osaka University Center of Medical Data Science and Advanced Clinical Epidemiology Investigator's Research Project for providing their insight and expertise for our research.

\section{Conflicts of Interest}

None declared.

\section{Multimedia Appendix 1}

Table S1. The algorithm for "fever" in the mobile app.

[XLSX File (Microsoft Excel File), 12 KB-Multimedia Appendix 1]

\section{References}

1. Public opinion survey on emergency medical services. Cabinet Office of Japan. URL: https://survey.gov-online.go.jp/h29/ h29-kyukyu/zh/z05.html [accessed 2021-06-22]

2. Eminovic N, Wyatt JC, Tarpey AM, Murray G, Ingrams GJ. First evaluation of the NHS direct online clinical enquiry service: a nurse-led web chat triage service for the public. J Med Internet Res 2004 Jun 02;6(2):e17 [FREE Full text] [doi: 10.2196/jmir.6.2.e17] [Medline: 15249266]

3. Eastwood K, Smith K, Morgans A, Stoelwinder J. Appropriateness of cases presenting in the emergency department following ambulance service secondary telephone triage: a retrospective cohort study. BMJ Open 2017 Oct 15;7(10):e016845 [FREE Full text] [doi: 10.1136/bmjopen-2017-016845] [Medline: 29038180] 
4. Sakurai A, Morimura N, Takeda M, Miura K, Kiyotake N, Ishihara T, et al. A retrospective quality assessment of the 7119 call triage system in Tokyo - telephone triage for non-ambulance cases. J Telemed Telecare 2014 Jul;20(5):233-238. [doi: 10.1177/1357633X14536347] [Medline: 24829258]

5. Katayama Y, Kitamura T, Hirose T, Kiyohara K, Ishida K, Tachino J, et al. Characteristics and outcome of patients triaged by telephone and transported by ambulance: a population-based study in Osaka, Japan. Acute Med Surg 2020 Nov 28;7(1):e609 [FREE Full text] [doi: 10.1002/ams2.609] [Medline: 33282318]

6. Statistics Bureau of Japan. Basic aggregate results. Census of Japan in 2015. URL: http://www.stat.go.jp/data/kokusei/2015/ kekka.html [accessed 2021-06-22]

7. Okamoto J, Katayama Y, Kitamura T, Sado J, Nakamura R, Kimura N, et al. Profile of the ORION (Osaka emergency information Research Intelligent Operation Network system) between 2015 and 2016 in Osaka, Japan: a population-based registry of emergency patients with both ambulance and in-hospital records. Acute Med Surg 2019 Jan;6(1):12-24 [FREE Full text] [doi: 10.1002/ams2.371] [Medline: 30651993]

8. The statistics of telephone triage service in Osaka, in 2019. Osaka Municipal Fire Department. URL: https://www. city.osaka.lg.jp/shobo/cmsfiles/contents/0000052/52526/R1nennpou.pdf [accessed 2021-06-22]

9. Kuriyama A, Ikegami T, Kaihara T, Fukuoka T, Nakayama T. Validity of the Japan Acuity and Triage Scale in adults: a cohort study. Emerg Med J 2018 Jun 13;35(6):384-388. [doi: 10.1136/emermed-2017-207214] [Medline: 29535086]

10. Fire and Disaster Management Agency of Japan. The protocol of telephone triage in Japan version 3. URL: https://www. fdma.go.jp/mission/enrichment/appropriate/appropriate002.html [accessed 2021-06-22]

11. Katayama Y, Kiyohara K, Komukai S, Kitamura T, Ishida K, Hirose T, et al. Relationship between the number of pediatric patients with rotavirus and telephone triage for associated symptoms. Am J Emerg Med 2021 Jan;39:6-10 [FREE Full text] [doi: 10.1016/j.ajem.2020.03.039] [Medline: 32241629]

12. von Elm E, Altman DG, Egger M, Pocock SJ, Gøtzsche PC, Vandenbroucke JP, STROBE Initiative. The Strengthening the Reporting of Observational Studies in Epidemiology (STROBE) statement: guidelines for reporting observational studies. PLoS Med 2007 Oct 16;4(10):e296 [FREE Full text] [doi: 10.1371/journal.pmed.0040296] [Medline: 17941714]

13. Li L, Lake R, Raban MZ, Byrne M, Robinson M, Westbrook J, et al. Medication-related calls received by a national telenursing triage and advice service in Australia: a retrospective cohort study. BMC Health Serv Res 2017 Mar 14;17(1):197 [FREE Full text] [doi: 10.1186/s12913-017-2135-1] [Medline: 28288619]

14. Venkatesh, Morris, Davis, Davis. User acceptance of information technology: toward a unified view. MIS Quarterly 2003;27(3):425. [doi: 10.2307/30036540]

15. Morimura N, Aruga T, Sakamoto T, Aoki N, Ohta S, Ishihara T, Steering Council of Tokyo Emergency Telephone Consultation Centre. The impact of an emergency telephone consultation service on the use of ambulances in Tokyo. Emerg Med J 2011 Jan 26;28(1):64-70. [doi: 10.1136/emj.2009.073494] [Medline: 20581386]

16. Jahn HK, Jahn IHJ, Roland D, Behringer W, Lyttle M, Paediatric Emergency Research in the United Kingdom, Ireland (PERUKI). Prescribing in a paediatric emergency: A PERUKI survey of prescribing and resuscitation aids. Acta Paediatr 2021 Mar 28;110(3):1038-1045. [doi: 10.1111/apa.15551] [Medline: 32869877]

17. Singh K, Drouin K, Newmark LP, Filkins M, Silvers E, Bain PA, et al. Patient-facing mobile apps to treat high-need, high-cost populations: a scoping review. JMIR Mhealth Uhealth 2016 Dec 19;4(4):e136 [FREE Full text] [doi: 10.2196/mhealth.6445] [Medline: 27993761]

18. Lepley B, Brousseau D, May M, Morrison A. Randomized controlled trial of acute illness educational intervention in the pediatric emergency department: written versus application-based education. Pediatr Emerg Care 2020 Apr;36(4):e192-e198. [doi: 10.1097/PEC.0000000000001719] [Medline: $\underline{\text { 30624425] }}$

\section{Abbreviations}

NHS: National Health Service

STROBE: Strengthening the Reporting of Observational Studies in Epidemiology

UTAUT: Unified Theory of Acceptance and Use of Technology

Edited by S Badawy; submitted 29.01.21; peer-reviewed by M Aoki, EM Noack, T Shirakawa, MC Lin; comments to author 14.03.21;
revised version received 08.04.21; accepted 12.05.21; published 30.06.21
Please cite as:
Katayama Y, Kiyohara K, Hirose T, Matsuyama T, Ishida K, Nakao S, Tachino J, Ojima M, Noda T, Kiguchi T, Hayashida S, Kitamura
T, Mizobata Y, Shimazu T
A Mobile App for Self-Triage for Pediatric Emergency Patients in Japan: 4 Year Descriptive Epidemiological Study
JMIR Pediatr Parent 2021;4(2):e27581
URL: $\underline{\text { https://pediatrics.jmir.org/2021/2/e27581 }}$
doi: $\underline{10.2196 / 27581}$
PMID: $\underline{34255709}$


(C) Yusuke Katayama, Kosuke Kiyohara, Tomoya Hirose, Tasuku Matsuyama, Kenichiro Ishida, Shunichiro Nakao, Jotaro Tachino, Masahiro Ojima, Tomohiro Noda, Takeyuki Kiguchi, Sumito Hayashida, Tetsuhisa Kitamura, Yasumitsu Mizobata, Takeshi Shimazu. Originally published in JMIR Pediatrics and Parenting (https://pediatrics.jmir.org), 30.06.2021. This is an open-access article distributed under the terms of the Creative Commons Attribution License (https://creativecommons.org/licenses/by/4.0/), which permits unrestricted use, distribution, and reproduction in any medium, provided the original work, first published in JMIR Pediatrics and Parenting, is properly cited. The complete bibliographic information, a link to the original publication on https://pediatrics.jmir.org, as well as this copyright and license information must be included. 